\title{
Return of the Repressed: Bong Joon-Ho's Parasite
}

\author{
Julia Ridgeway-Diaz ${ }^{1} \cdot$ Thanh Thuy Truong $^{1} \cdot$ Glen O. Gabbard ${ }^{1}$ \\ Received: 16 April 2020 / Accepted: 8 September 2020 / Published online: 22 September 2020 \\ (C) Academic Psychiatry 2020
}

The film critic Parker Tyler once noted that the movie house was the psychoanalytic clinic of the average worker [1]. In the darkness of the movie theatre, we lower our guard and allow the unconscious process associated with dreams to surface. We re-experience our childhood terrors at a safe distance. We imagine that we can soar through the universe with the unencumbered ease of the characters on the screen. Perhaps most of all, we can fulfill our longings for a life that is very different from our own existence affected by the slings and arrows of frustration and defeat.

The cinematic setting creates the possibility of reworking frustrations, conflicts, and traumas that have been repressed in the service of functioning in society. Repressed content lurks just below the surface, motivating our behaviors without our knowledge. Through the mirror of the screen, we identify with aspects of the characters and experience a revival of hidden desires, fears, and past disappointments. We find ourselves momentarily transported to a territory both unknown and familiar. Director Bong Joon-Ho's masterpiece Parasite, winner of the Academy Award for Best Picture last year, captured audiences of many classes and nationalities through its intricate examination of universal psychological themes [2,3]. Parasite creates a playground within which we can safely explore dangerous questions about ourselves and the world we inhabit.

Psychotherapy and cinema have long been regarded as kindred spirits by psychoanalytic scholars. Indeed, a psychodynamic interpretation of Parasite provides a heuristic approach to understanding the psychological dilemmas faced in a capitalistic society that are often deeply repressed by its denizens. Using film to teach psychodynamic concepts to trainees increases accessibility to the ideas, particularly in psychiatry residency programs with a limited focus on psychodynamic psychotherapy. In clinical psychiatric practice, the patient's inner world may not emerge until years into treatment, an

Thanh Thuy Truong

tt5@bcm.edu

1 Baylor College of Medicine, Houston, TX, USA opportunity that may not always present itself to trainees. Thus, a relevant film may provide a practical didactic introduction to psychodynamic theory. In this article, we explore the intrapsychic defense of repression, which is defined as blocking unacceptable ideas or impulses from consciousness. This defense is universal and protects against unwanted feelings. Moreover, we explore the potential damage repression can cause when left unexamined. It is critical for residents to understand this defense because it is pervasive in psychiatric practice. For purposes of psychiatric education, residents can watch the film, read the article, and examine repression in patients and society. The instructor can apply lessons from the film to specific patient cases or broaden the scope of the discussion to global issues. Additionally, the film be part of a film series used to illustrate various psychodynamic concepts or as a stand-alone depiction of repression in a seminar.

\section{The Narrative}

The following is a brief summary of Parasite. The narrative begins with a descent from ground level to meet the Kim family in their cramped, squalid home in a rundown part of town. By chance, the son Ki-woo is given the opportunity to pose as a college student and tutor the daughter of the extremely wealthy Park family. Ki-woo and his sister Ki-jung devise a plan to trick the Parks into hiring every member of their family as replacements for their previous servicers. Pretending to be unrelated, each plays their assigned role with remarkable skill. Ki-jung poses as an art therapist trained in the USA. The father Mr. Kim is hired as the replacement chauffeur. The mother Chung-sook replaces the old housekeeper Moon-gwang, whose dismissal resulted from the Kim family's precisely orchestrated indictment. The Kims celebrate their successful infiltration with a night of gourmet food and liquor in the Park home while they are away, only to be jolted by Moon-gwang's return. Tattered and deplorable, she begs to enter the house. In a remarkably symbolic turn of events, Moon-gwang reveals that her husband Geun-se has been secretly residing in a basement within the Park home. 
She quickly turns the tables on the Kims and threatens to disclose their scheme to the Parks.

The film then descends into a nightmarish scenario that leaves the audience unsettled as they drive home from the theatre. Set in hyper-capitalist South Korea, the film portrays two families attempting to navigate the socioeconomic structure that is both imposed upon them and created by them. Judging by its success throughout the world, we can infer that the film has universal appeal. As Bong observed, "we all live in the same country now: that of capitalism" [4]. Though Parasite begins as an engaging, often funny story about a scam pulled off by a family of con artists, it gradually develops into a magical realist tale that is, in fact, a parable about identity and greed. Themes of repression, envy, class differences, power, violence, wishes and fears - both conscious and unconscious - enthrall the audience as they join the world of the characters, even when that world is dark and unpredictable.

Just as children internalize schemas taught to them by their parents, citizens of capitalist societies also internalize cultural schemas. In the USA, the prevailing mantra is that hard work leads to success. Hence wealth is deserved based on merit, and poverty connotes laziness and idiocy. This belief is deeply ingrained even though we know it is often not true. We try to work through the tension between what we want to believe and what we see. Parasite, by juxtaposing the poor, cunning, and dishonest Kim family with the wealthy, gullible, and straightforward Parks, gives the audience an opportunity to live in a world in which the lies about capitalism are laid bare. Characters are portrayed in all their complexity regardless of class, allowing the audience to identify with both poor and rich, dreamer and cynic, trickster and mark - all facets of ourselves we may lock away.

\section{Return of the Repressed and the False Meritocracy}

The film weaves a chronicle of class stratification and the human psyche into the architecture of each family's home. The Park family home is perched at the top of a hill, unmarred by the hustle and bustle of the city. The interior is serene and sanitized, devoid of grime on the walls, and strangely, also devoid of a toilet. It is as though the Park family has no excrement to eliminate. Yet, unbeknownst to them, the home has a dark basement in which a ghost-like figure, Geun-se, resides. Left out of the blueprints, the basement can be viewed as a disavowed, "not-me" portion of the unconscious, one that cloisters repressed urges and longings. Geun-se, barely surviving in the basement, is the antithesis of the perfect Parks. Filthy and abject, Geun-se focuses solely on survival. In this sequestered space, one finds a toilet, a stack of condom wrappers, and a shrine of important figures, with Mr. Park's picture at the top. Capitalism - in all its neoliberal, meritocratic glory-is the new God. Locked in the basement, Geun-se represents the id that has been repressed.

Symbolizing the transformative power of wealth, the Parks project an image of transcendence, free of shame, and unsightly animal instincts of aggression, lust, and waste. There is even a conspicuous absence of unpleasant odors. The yearning for transformation is part of our shared developmental journey, and capitalism is sold as the means to that end. The Kim family, constricted in their small semi-basement home where the bathroom coalesces with the living room, cannot so easily hide their basic nature. Deception is justified as necessary for survival, accepted as a wrinkle in character that has not been ironed out by money.

The false meritocracy of capitalism breeds contempt and envy between the classes, further reinforcing the divide between them. The interaction between Geun-se, Mr. Kim, and Mr. Park sketches the interclass dynamic within our actual economic hierarchy. Mr. Kim is portrayed as passive and avoidant whereas Mr. Park is the potent alpha male, a titan of industry. Despite this polarity, Mr. Kim attempts to level the playing field by befriending Mr. Park against the backdrop of his deceit. Meanwhile, Mr. Park maintains vigilance against this unwelcome closeness. The relationship between the two patriarchs involves devaluation and idealization, each asserting his artificial superiority in vain. Geun-se, symbolic of the invisible lower class, basks in the glow of affluence. While Mr. Kim pities him, Geun-se considers them no different as they both battle for scraps at the bottom of the podium. Dignity is a commodity, priced at predetermined levels unattainable when starting from too far below. To avoid degradation and humiliation, each character employs intrapsychic defenses that are expressed in a variety of ways, ranging from verbal jabs to murder.

Bong teases with moments of equivalence between the Kims and Parks. Revealed to be dilettantes, the Park couple's inquisition of their chauffeur's sex life with a drug user is hypocritically replaced by fetishizing the scenario. The Parks are precisely one soiled laundry item away from the Kims, whose human odor is not as well concealed by the perfume of wealth. Neither family is invulnerable to eruptions of the repressed unconscious. The Kims, feeble against their exploding toilet when their neighborhood floods, literally and metaphorically become submerged in their own waste as their scheme unravels. For the Parks, their repressed content in the form of Geun-se escapes and wreaks havoc on the picturesque garden party in a bloody denouement. Repression and denial engage us in repetition of cycles without awareness, condemning us to recreate internal conflicts and transfer them to the next generation. Bong elicits hopelessness in his use of cyclical imagery. The most notable example of this is the final scene, which begins with a reiteration of the opening descent into the Kims' home, eerie in its sameness and a jarring shift from Ki-woo's fantasy of success. Tragic in his youthful 
naiveté, Ki-woo clings onto a dream that is unrealizable. We wonder if his father also had this vigor in his youth, worn away by failed efforts to climb a ladder trapped in quicksand.

\section{The Great Equalizer}

The threat of annihilation permeates the unsettling atmosphere of the film, which sprinkles references to the eternal specter of nuclear attack from North Korea. The basement itself was built to save the wealthy inhabitants from an otherwise certain death. We all wish to have the power to defeat death and in doing so create spaces within ourselves that fester and grow in malignancy when not exposed to the light of day. The basement that did not make the blueprint is a marvelous cinematic device in Bong's narrative. The Parks, oblivious to their own unconscious, fall victim to its destructive force precisely because its contents were hidden and unknown. In the consulting room, when a patient's defense mechanisms eventually wear thin, the patient can become overwhelmed as he faces the emergence of his own grotesque Geun-se. Conversely, in a well-conducted psychoanalytic or psychodynamic treatment, the patient is gradually made aware of those warded-off areas within the psyche at a pace the patient can handle. In the film the "shit" erupts out of the toilet in an uncontainable manner, while in a systematic therapeutic setting, psychological "shit" is gradually revealed to the patient according to the patient's capacity to process it.

Whether it be economic oppression, nuclear decimation, or our current global boogeyman, coronavirus disease of 2019, none of us is truly spared from the potential horrors of existence. In the time of the coronavirus pandemic, the commodities money can afford are futile against this invisible invader. Consumers in the USA ward off helplessness with a range of strategies from denial to overshooting provision planning. Like in Parasite, Mr. Park's business empire was equally unable to protect him from death. The arbitrary nature of the pandemic - who it kills and who it spares - parallels the fragile nature of our fate as echoed in the film. In our current world, Mother Nature is just as bleak and capricious as human nature. Bong's use of cyclical imagery, random violence, and doomed fantasy speaks to the film's nihilistic motif. We all find ourselves trapped in cycles of behavior and fate not entirely of our own choosing. Perhaps the film's ability to resonate with so many viewers around the world is due not only to the common experience of capitalism but also to a shared confrontation of our own tragic helplessness in the face of death.

Acknowledgments The authors have informed the journal that they agree that both Julia Ridgeway-Diaz and Thanh Thuy Truong completed the intellectual and other work typical of the first author.

\section{Compliance with Ethical Standards}

Disclosure On behalf of all authors, the corresponding author states that there is no conflict of interest

\section{References}

1. Gabbard GO, Gabbard K. Psychiatry and the Cinema. Washington DC: American Psychiatric Publishing; 1999.

2. Parasite. Dir. Bong Joon-Ho. Barunson E\&A, CJ Entertainment; 2019.

3. The Atlantic: Parasite Won So Much More Than the Best Picture Oscar. Available at: https://www.theatlantic.com/culture/archive/ 2020/02/parasite-oscars/606310/. Last accessed 15 Apr 2020.

4. Hollywood Reporter: Bong Joon-ho talks true crime, Steve Buscemi, unlikely success of 'Parasite'. Available at: https://www. hollywoodreporter.com/news/bong-joon-ho-parasite-success-truecrime-steve-buscemi-1248655/. Last accessed 15 Apr 2020.

Publisher's Note Springer Nature remains neutral with regard to jurisdictional claims in published maps and institutional affiliations. 